\title{
Once Media Texts Meets Realism through Experimental Short Film
}

\author{
Mohd. Nor Shahizan Ali ${ }^{1}$ \\ Email Address: shahizan@ukm.edu.my ${ }^{1}$ \\ Centre for Research in Media \& Communication (MENTION) \\ Universiti Kebangsaan Malaysia ${ }^{1}$
}

\begin{abstract}
Adolescent in particular, have a radically different capacity to read media texts. Hence the true validity of each problem held by the media texts contributes to uncertainty in the interpretation process of the text. In line with the rapid growth of information technology, what was supposed to make information more available has resulted in more ambiguity among the adolescent in making sense of a message, especially experimental-oriented short films regarding realism issues. This paper examines the adolescent's understanding of the experimental short film 'KEEP GOING (2016)' through focus group discussions. The argument focuses on the surrounding environmental context, the everyday reality perspective and the overall view. With the abundance of cultural, technical constraints and the influence of foreign cultures; findings prove that the adolescent in daily life is naturally exposed to the media climate and being able to understand the sense of reality in an experimental short film.
\end{abstract}

Keywords: media texts, experimental short film, media climate, focus group discussion, media technology, media literacy, KEEP GOING.

\section{Introduction}

Knowledge is a critical requirement in any practice of human communication since the life of mankind. The evolving environment of distribution of information by value (whether public or individual) from time to time is in keeping with the correct context. Technology plays an important role as a catalyst in changing the flow pattern in combination with the creation of time and communication activities for knowledge delivery. Development depends on the technology's ability to transmit information and information exchange patterns between network administrations [4], [13].

Meta data becomes a media tend to have been consistent with the times and driven changes in the type and content of the information. These changes are important particularly when the information in the form of icons, audio, visual, graphics, and text description has become more compact according to the correct medium. Potter (2019) argued that the distribution of knowledge through a variety of media makes the context of the knowledge difficult to understand [13]. According to Renee (2010), the most successful alternative for ages has been using the visual to communicate as a means of information [15]. Nevertheless, information distribution in the context of a visual approach has evolved in line with the technological changes [8], [10]. When human culture advances expansively; visual presentation structures are becoming more advanced, so that it can be viewed anywhere. Evolutionary evolution of the transmission of knowledge by visuals can be seen by looking back to the most ancient process, beginning from the walls of the cave, turning on the television and computer and now to smartphones [1], [10], [7]. 
Smart phones today played a critical role as a tool for information dissemination. Numerous applications that can be used via a smartphone have emerged on the value of information and the knowledge about the target customer. Developing this technology allows the variety of information types which can only be accessed by the use of a smartphone. The new millennium is the largest generation which uses a smartphone to access information. Therefore, it means they have been opened to the open and public collection of information [2], [7], [8], [12], [13].

Developing this technology would implement users to choose the knowledge channel (medium) that corresponds with the knowledge they are searching for. This situation occurs due to the availability of multiple forms of communication in an attempt to give the audience knowledge. The audience basically consists of the new millennium which is given various details, particularly in the form of audio-visual to discuss certain issues. The new millennium therefore needs to be knowledge-savvy (high degree of visual literacy); so that they did not misunderstand the knowledge they got [2], [3], [8], [9], [13]. That aspect will allow the audience to respond in a sense of decision taking as a literate audience.

Visual literacy is an important part of the aspects found in media literacy research. Many people believe that the word literacy is just about 'printing', which is about throwing light on one's ability to read [2], [5], [6], [8], [13]. Through the use of the word 'visual literacy' [10], [12], [13], [16] the term literacy can be applied to other communication outlets such as film and television. Studying visual literacy on the film and television medium can contribute to a variety of work within the broadcast industry. The visual content impacts heavily on the creation of experimental short film knowledge research.

Experimental short film is a development of tools that can provide audience awareness consistent with visual literacy concepts proposing that the 'audience will obtain information literacy exposed to them' with each information literacy. In at least three instances, viewers are searching for useful information; news, industry and the results [2], [10], [13], [14]. Content helps viewers to realize that the work is constructed on the basis of certain standards which do not neglect the service's truth. On the level of the industry; people need to recognize that the media is a company with funding from a specific group [1], [6], [13], [15]. Although the group needs to understand from the point of impact that each individual has the capacity to interpret each message on a personal level. It is clear that all the information provided to the audience does not have the same comprehension capacity as it depends on the perception of the information [2], [9], [15].

Today, the emergence of numerous futuristic experimental short films uses a realistic approach and uses reality as narrative such as 'KEEP GOING (2016)' Yeonhee's action/science fiction story, whose implanted artificial heart is broken, and Margo, a robot who linked Yeonhee's broken heart with his body. With a common inseparable destiny, the two are going towards the frontier and on to life. It's weapons, robots, and the coming-of-age assume that in everyday life realism in the adult, a search equally for an alternative. The work of experimental short films is thus especially noteworthy because it contains symbols that indicate meaning. To date, audiences that consist of new millennium are subject to the influx of information from a variety of media outlets. In reality they are showered differently with philosophies than they have formally studied in education. The advent of futuristic experimental short films has, among 
other things, created uncertainty for this new millennium to reconcile all of this with their perception of the actual facts [2], [3], [16]. This gap is filled with certain studies in media literacy skills for various types of experimental formed audio-visual content short film work for building meaning among the new millennium.

Many of past research have shown that new millennium is the savviest internet user [2], [11], [15]. Because the information gathered from the Internet affects a lot of them, their mindset is different as compared with the previous mindset. They have a practical approach to thought, and are straightforward. Therefore, with the abundance of new media knowledge; studies are required to identify how trends of new millennium reading are present on audiovisual materials (such as experimental short film). Additionally, many emerging experimental short films come in an array of alternative platforms (such as Youtube) that touches on realism issues in everyday life. The new millennium now only reads about the secondary realities without witnessing them firsthand. Because of this, the need to review the new millennium reading of experimental short film materials that touch on daily life issues (especially realism) is a necessity.

Heywood \& Sandywell (2005) and Lester (2003) considered that the visual dimension is a reinforcement of a device's stereotypic image [3], [5]. The inference is that when a person is marked by gender, age, cultural background, economic status or physical disability can be misleading. This is because the capacity of emotional visual impact is higher than words, as images will remain long in the mind. However, this assertion is focused solely on visual elements that rely not on visual perception of a visual element but on imaging. The material in the form of audio-visual materials was not specified, whereby the producers did not elaborate the construction of meaning [4], [6], [10]. Therefore, there is an obvious gap in the relationship between the literacy skills of reading processes through audio visual materials, especially on experimental short films about the issues of everyday life (such as realism) to the present new millennium.

\section{Research Method}

Twenty-seven informants (consisting of thirteen boys and fourteen girls (three groups) was assigned for focus group discussion with the task of watching the experimental short film 'KEEP GOING (2016)'. The group distribution for the focus group discussion is based on field of study, consist group A (Arts Stream), group B (Professional Stream) and group C (Science Stream). The analysis is descriptive in some interesting aspects related to cognitive and aesthetic elements used and the acceptance of informants to show an experimental short film on the construction of their views on the realism in daily life. This study focuses on two primary votes on decoding (reading) the experimental short film's 'KEEP GOING (2016)'. The first assessment is to determine the visibility of the realistic dimension. Secondly, to assess the informant's reaction to the narrative message provided by the experimental short film.

\section{Result}

\section{First Analysis}


Experimental short films have been one of the media texts for transmitting practical knowledge [2], [9], [13]. The informants back up this argument as follows:

Boy A (Group A): Experimental short film, I think to tell about realism that aired just for the purpose of something, in particular. As in KEEP GOING for example ... In my personal view it reveals clearly that in the current situation the director uses established atmosphere for his benefit in transmitting messages. Although it is said, saying that this allegedly current environment (technology blast) for the good of society at that time was in place, but it was actually behind the scene in silence to maintain its main objective of defining the new millennium tied to technology. I don't deny the statement is right, but not all of the experimental short film focuses on the real situation.

Boy B (Group B): This short film tried to establish a sense of consciousness. But no doubt it is all realism. When we look at the present situation, though, it's more politics. Since the main contents wanted the new millennium unconscious not to get separated, and to help one another.

Girl A (Group B):Agree, virtually everyone I know some experimental stuff, because people through things that don't go off anymore. So, only depend on directors to retell. Therefore, the director must take the opportunity to bring it into a development of realism.

Boy $C$ (Group A): I saw the propaganda director's on how to attribute development empowerment. For me in my own view, life is simply the reason why people accept realism as it is the way of life because of the blast of technology that has branded all kinds of realism in mind of the new millennium. Yet director's carried along the philosophy we have to embrace. But how they wanted us to be free suggests there is a pure purpose.

Girl B (Group A):Yeah, because that's when we study the history of fighting film, I realized America was amazing.

From there, we can see that the American director is attempting to use realism as a weapon to claim what it needs.

Girl C (Group A): Depends, they are more attractive to them from outside if possible, a second thought to change the way we make them more pro...Perhaps.

This suggests that not all experimental short films are popular to the general audience. Likewise, most informants note that technology plays a major role in promoting audience reading in the current scenario. The director's key concept should be viewed by the viewer in the spirit of the reality they've encountered in their daily lives. The strategy undertaken by the director poses a number of reality concerns and informants are able to absorb all the details because of the presence of technology. This current scenario makes informants more literate and they are aware of the importance of realism depicted by the experimental short film.

\section{Second Analysis}


This experimental short film introduces various methods within informants with the current information. This experimental short film chronicles the real-life current situation from the point of view of adolescent, based on a real story. The audience was thus under the assumption that there was a connection between philosophy and technology [4], [7], [8], [12]. Evident reported as follows:

Boy F (Group C): Because of the current technology, this sort of realism tells the truth I used the authority of my family...That's true .. When a man says to his father, willing God, he believes it. In reality, he says when he saw in a real story at one time ...especially the ideological film... Time he has an ideology tale, he has little to tell about how films actually execute the ideology to persuade the audience. I mean, I'm talking really ...How should they have said that ...There are no different men, but they discriminate by ideology ... So, I kind of reconsider, when I saw a novel, the other drama, the ideology plays a major role. And, for me, I believe my dad's point of view.

Girl D (Group A): Books ...Read more... Not used politics to close schools ... Teacher of history said something like this ...This is the case ...And why sometimes stuff ... philosophy that they have carried wearable ...Yet occasionally, the experimental short film tried to inhibit the use of specific methods.

Boy A (Group C):To me ...Just the experimental strengthening, maybe because of philosophy, but it's just one target to assert ...Take power to the audience ...That is the whole thing. The only way to exploit the reality issue, ...That is the whole thing.

Boy H (Group C): What kind of education it is, but if it includes school time, we have applied ...Teacher teaching already, we just embrace what people claim it's like that time ...It's fantasy dramas ... Before that I kind of get a little higher, a wide variety of examples now, we may imagine there are some kind of dramas that are interesting.

Girl I (Group A): I first heard about the experimental at school, then I began to get other knowledge from outside peers, from family storytelling, then from the internet ...So much of the knowledge is the same which is a lot of theoretical philosophy injection.

Girl E (Group C): I just got out of school

Girl F (Group B): school ...

This experimental short film has been proved to say the truth about ideology as a person searching for realism. According to (Renee 2010), "the importance of the experimental as a propaganda tool, public education, and the distribution of ideas for educating people in a range of subjects" [15]. For this situation, the study is fully influenced to the audience generally because they conclude that technology is a big factor that leads the experiment's philosophy. Via regular presentations on the topics highlighted, new millennium informants have the expertise and information they have learned and acquired. Since new millennium informants have access from the point of technology, their perception is focused on each individual's expertise and experience (didn't receive any information transmitted directly, but look at the context behind it) [9], [14], [16]. 
After watching the experimental short film, there are some impacts caused to the audience which include the rejection of the notion that labels life through the relation of current technology. In general, informants claimed that the freedom of technology is also realism. The statement has the following proof:

Girl C (Group C): As this realism, it exists in the world, not only seen in Malaysia, and carries with it a special framework of life realism.

Boy G (Group B): To me it's an philosophy of realism. So we have to have our dream when the philosophy or thinking of the call. So, as we said to the new millennium, it's also called struggle and it remained to fight for something ...

Girl A Group C): I believe yes. Even when in Malaysia, the struggle to make technology important to all, so that Malaysia's new millennium culture recognizes the fact that the technology is effectively applied through some innovative work.

Girl D (Group C): Sure, and it's not just a conflict but an idea built around the world for the same purpose. Realism still lingers inside the person until today.

Media texts element does not influence the new millennium of experimental short film perception. This assertion is consistent with (Baran 2013), which notes that any media material can be viewed as a sign-in document [2]. These signals are arranged in different ways and are interconnected. The recipient must be able to read the signals and also the meaning of the texts when reading the media texts [1], [3], [9]. For example, when you read one paragraph, not only do you have to turn to its own words, but you also have to analyze the verse's overall structure to understand it thoroughly.

Mohd. Nor Shahizan et. al (2019) and Potter (2019) have agreed with this view, which indicates that the person should have strong knowledge systems and information gathered from the real world, rather than only information from mass media [10], [13]. Moreover, to become important media users the person also requires a good knowledge of the system itself. So people need to know their personalities clearly in the two styles of consciousness style of personal experience and personal ambitions, to distinguish themselves from the mainstream culture and personal viewpoint on the mainstream. There are two types of knowledge needed at the locus of each person. Good and organized information can help individuals make choices wiser and fairer, without being informed solely by the content of the mass media [6], [7].

\section{Discussion}

The public must consciously perceive emotions, incidents and circumstances, based on their interpretation. We will also exchange thoughts, feelings and experiences in evaluating and reacting using symbols [2], [3], [5]. The focus group findings reflect a mixture of shared awareness (in technology community groups) and education, and the prevalence of individual cultures as a particular factor. This research clearly demonstrates the significance of each of these factors for the production of individual audio visual.

Others' education, reading, and observations had established shared understandings of informants. It also offers knowledge and lessons about the surrounding impact whether formal 
or informal, namely the specific factors that condition individual cultures derived from group leaders, family members, and friends. Thus all these variables were put together in a box by partnership, and had become a normal process (mental configuration).

Potter (2019) suggests that a person should have a strong system of awareness and information from the real world, rather than information from the mass media alone [13]. The framework of a solid knowledge of the individual self is needed for being a critical media consumer. To learn more about the individual's personality, two forms of consciousness in the individual locus, such as personal awareness style and personal ambitions required to differentiate from the media world and personal media viewpoint. This is because a strong information system would allow individuals to make better choices and fairer decisions that should not be determined solely by the mass media content [1], [11], [15].

Study by Potter (2019) found that the construction of individual meaning is affected by each individual's style of personal awareness and personal goals [13]. So that, the model shows that individuals affected by the combination of shared awareness (in technical community groups) and education as the uniqueness factor prevalence of individual cultures condition that they have access to a variety of knowledge using a variety of approaches to view reality and ideology (everyday life). However, they look at the factors that the philosophy can bring to the daily life of the person. To them (read as: new millennium), the benefit of technology enhancement was to overcome the prejudices and values of individuals that reality is a fight to individual freedom.

According to Baran (2013) and Mohd. Nor Shahizan Ali et. al (2019), most of the content can be interpreted in many ways; but usually the message sender is intended to control an audience in making interpretations dependent on the view when they deliver the message. However, without being affected by the social class, the viewer may make a different interpretation, and they may not agree or misunderstand certain aspects of a message and end up creating an alternative interpretation that is different from the producer's view [2], [9]. This view supports the informants' intervention acknowledged that the combination of shared knowledge and education also the uniqueness factor prevalence of individual cultures in building the significance of the experimental short film. They prefer to judge life as reality based on the technological effects and awareness that they are gathering all this without being swayed by the alternative interpretation.

The impact of peer influence and current information affect the new millennium method of reading text. Both of these effects contribute significantly to the new millennium process of audio visual perception of substances [2], [6]. This argument is focused on the nature of the information that relies on the social cognitive psychology to generate information meaning and interpretation, and is implemented automatically and does not provide flexibility in the interpretation of the information. It is not surprising that this study demonstrates that the combination of shared knowledge and education and the uniqueness factor dominance of individual cultures leads individual informants not to be influenced by media materials seen in total, but to assess content based on awareness and long-standing self-support over the years.

These results agree with Kress \& Leeuwen (2006) and Prince (2012), which claim that each visual image has its own semantic sense by providing a personal relationship with the viewer and the object. The relationships are very good so that decision taking based on shared 
understanding of a material to be assessed will affect the reader [4], [14]. Heywood \& Sandywell (2005), McQuail (2005) and Messaris (2004) assume that this shared understanding is often very closely related to the cultural traditions and not affected by the analyzed content [3], [7], [8]. They also suggest consumers should carry established information together with the content gathered for assessment during their lives and experiences [3], [7], [8]. The university study area does not impact the readings of experimental short film by the informants (realists).

\section{Conclusion}

In conclusion, the rapidly evolving technology influenced the new millennium from the point of explicit and implied, to a more critical understanding of the content [10], [12], [15]. This community is very interested in social media and has access to high technology. The pattern of their understanding of each question, involving the ideology in particular, is different. In debating critical problems their approach is more practical and transparent [15], [16]. The impact transformation of their thinking (the new millennium) should be taken seriously by the state leaders, particularly in the process of putting in place any new policy that relates to the party. They (the new millennium) not just to make interpretations based on the experience and the environment, but also through the use of IT skills to find and analyze the facts of each person relevant to the experimental short film. This scenario is concluded as the media climate.

Potter (2019) notes that the media's message has several elements on the state of the real world that influence the audience (read: the new millennium), but it also has elements that cause the audience to depart from the real world situation [13]. Television and movies aren't fascinating visual waives like thought about yourself, reading, walking and other things that do a lot of static in daily life [6], [12], [16]. However, the creator presents the image that can draw the most viewers to see their problems (read: the new millennium). Most companies produce non-visual reality related programs. In the visual depiction of truth the situation is different. Visuals showing truth contained acts that actually occurred and this involves awareness and skills to interpret the visual truth context [2], [4], [10].

Understanding and interpretation partly relies on a starting point to integrate crucial views that have historically been overlooked by media academics (the mechanisms of understanding), whereas cognitive psychologists have historically disclosed the socio-cognitive approach to understanding but have overlooked the mechanisms that provide interpretation. Relandscaping should be emphasized that the viewer's perception is a process variable that differs automatically from one another [2], [6].

\section{References}

1. Al-Amril Othman \& Mohd. Nor Shahizan Ali. Misinterpretation on rumors towards racial conflict: a review on the impact of rumors spread during the riot of May 13, 1969. Jurnal Komunikasi, 2018, Jilid 34(3): 271-282.

2. Baran, S.J. Introduction to mass communication theory: Media literacy and culture. $7^{\text {th }}$ Edition, McGraw-Hill, CA: Wadsworth Publishing Company. 2013.

3. Heywood, I. \& Sandywell, B. Interpreting visual culture: Explorations in the hermeneutics of the visual, $2^{\text {nd }}$ Edition, Routledge, New York. 2005. 
4. Kress, G. \& Leeuwen, T.V. Reading images: The grammar of visual design. $2^{\text {nd }}$ Edition, Routledge. New York. 2006.

5. Lester, P.M. Visual communication: Images with messages. $2^{\text {nd }}$ Edition, Thomson Wadsworth. Belmont, CA. 2003.

6. Livingstone, S. 'On the material and the symbolic: Silverstone's double articulation of research traditions in new media studies', New Media and Society, 2007, 9(1), pp. 1624.

7. McQuail, D. Mass communication theory, $5^{\text {th }}$ Edition, Sage Publications, London. 2005.

8. Messaris, P. Visual literacy: Image, mind, \& reality, $2^{\text {nd }}$ Edition, Westview Press, Boulder CO. 2004.

9. Mohd. Nor Shahizan Ali, Junaidi Awang Besar, Novel Lyndon, Abd Hair Awang \& Neesa Ameera Mohamed Salim. Audience Interpretation of Climate Change Documentary. Jurnal International Journal of Advanced and Applied Sciences, 2020, 7(3) 2020: 37-44.

10. Mohd. Nor Shahizan Ali \& Neesa Ameera Mohamed Salim. The arts of social reality (RE) construct individual mindset of post-independence community via historical documentary. Jurnal Humanities \& Social Sciences Reviews, 2019, Vol 7(2): 270-275.

11. Mohd. Nor Shahizan Ali \& Ahmad Munawar Ismail. Konstruk Pelaporan Pemikiran Isu Liberalisasi Agama dalam Portal Berita Harian dan The Star. Jurnal Komunikasi, 2017, Jilid 33(1):229-241.

12. Morgan, S.J. 'More than pictures?An exploration of visually dominant magazine ads as argument', Journal of Visual Literacy, 2005, 25(2), pp. 145-166.

13. Potter, W.J. Media literacy, $9^{\text {th }}$ Edition, SAGE Publications Ltd, London. 2019.

14. Prince, Stephen R. Movies and Meaning : An Introduction to Film. $6^{\text {th }}$ Edition. Virginia Polytechnic Institute and State University. USA. 2012.

15. Renee, H. Digital and Media Literacy: A Plan of Action, The Aspen Institute, New York. 2010.

16. Sturken, M. \& Cartwright, L. Practices of looking: An introduction to visual culture, Oxford University Press. New York. 2003.

\section{Acknowledgements}

This research is supported by the MPOB research grant EP-2017-060. 